\title{
Recurrent Benign Granular Cell Tumor of Breast with Malignancy - Does it Exist?
}

\author{
Kumaran $\mathrm{D}^{*}$, Manikandan $\mathrm{A}^{1}$, Umesh $\mathrm{V}^{1}$, Vallonthaiel $\mathrm{AG}^{2}$, Pradeep $\mathrm{I}^{2}$ and Gupta $\mathrm{S}^{1}$ \\ ${ }^{1}$ Department of Radiation Oncology, All India Institute of Medical Sciences, New Delhi, India \\ ${ }^{2}$ Department of Pathology, All India Institute of Medical Sciences, New Delhi, India
}

${ }^{*}$ Corresponding author: Kumaran D, Department of Radiation Oncology, All India Institute of Medical Sciences, New Delhi, India, Tel: +919910111323, E-mail: damodar.dr@gmail.com

Citation: Kumaran D, Manikandan A, Umesh V, Vallonthaiel AG, Pradeep I, et al. (2016) Recurrent Benign Granular Cell Tumor of Breast with Malignancy - Does it Exist? J Cancer Sci Clin Oncol 3(1): 102. doi: $10.15744 / 2394-6520.3 .102$

Received Date: January 04, 2016 Accepted Date: June 07, 2016 Published Date: June 09, 2016

\begin{abstract}
A granular cell tumor of the breast parenchyma is a rare tumor accounting for 5-6\% of all granular cell carcinoma and are mostly benign in nature. The malignant granular cell tumour is rare tumor that comprise 1-2\% of all granular cell tumors. This is a case of a 35-year woman who presented with a palpable mass in the right breast. On wide local excision, a diagnosis of benign granular cell carcinoma was made. On follow up, with a disease free interval of one year, she developed local recurrence and she underwent simple mastectomy with adjuvant radiation therapy. Histopathological examination, confirmed benign granular carcinoma. This is one such case where histologically confirmed to be benign, but the clinical behaviour of the tumour favoured malignant variety. Hence adjuvant therapy should be considered for this benign appearing, malignant tumour.
\end{abstract}

Key words: Granular cell tumor; Breast with Malignancy; Cell carcinoma

\section{Introduction}

Granular cell tumour [GCT] or Granular Cell Schwannoma of the breast is a rare benign tumour of the neural cells. It is commonly noticed in the oral cavity and other soft tissues [1]. About 5-8\% of GCTs occurs in breast [2]. Most of the GCT in the breast are benign in nature and occurrence of malignant GCT is even rarer. We encountered a GCT in the breast of a pre-menopausal women which morphologically did not show any conventional features of malignancy but it acted in an aggressive fashion. The aim of this case report was to increase awareness of the existence of a rare benign looking variant of GCT with clinical aggression.

\section{Case Report}

35 year lady from Faridabad presented with a lump in the right breast of two years and developed pain in the lump for the past 2 weeks. She did not give any history of nipple discharge or any other swelling in the body. On evaluation, the mammogram showed BIRADS score of 4 in the right breast. Clinically examination revealed a mobile lump in the upper outer quadrant of right breast measuring $2 \times 2 \mathrm{~cm}$ with no axillary nodes. Biopsy of the lump showed tumour tissue arranged in a diffuse sheet, composed of polygonal cells with abundant eosinophilic cytoplasm and round nuclei with inconspicuous nucleoli. Nuclear pleomorphism, mitosis or necrosis were not seen. These cells were immunopositive for S100, CD 68 while immunonegative for cytokeratin with $\mathrm{Ki}-67$ of $0-1 \%$. Hence a diagnosis of benign granular cell tumour was made.

She underwent wide local excision of the lump on 15.01.2013. Post-op HPE showed Grossly, the tumour was circumscribed and measured $3 \times 3 \times 2 \mathrm{~cm}$, confirming the diagnosis of benign granular cell tumour. Resection margins were free of tumour

She was kept on follow-up. In January 2014 she developed a lump in the upper outer quadrant of the right breast. With clinical suspicion of recurrence, biopsy of the lump showed benign granular cell tumour. She underwent completion mastectomy and axillary nodal sampling on 05.02.2014. Postop HPE showed tumour measuring $4 \mathrm{x} 3 \mathrm{~cm}$ with histomorphology similar to the previous excision. Features of malignancy like spindling, nuclear pleomorphism, prominent nucleoli, necrosis, mitosis were not seen. These cells were immunopositive for S100, Calretinin while immunonegative for cytokeratin as shown in the Figure 1. Margins were free of tumour and all the 13 nodes are negative for metastasis.

She received post-op radiotherapy to the right chest wall of $45 \mathrm{~Gy}$ in 25 fractions. She was kept on follow-up. After 16 months of follow-up, she is disease free. 


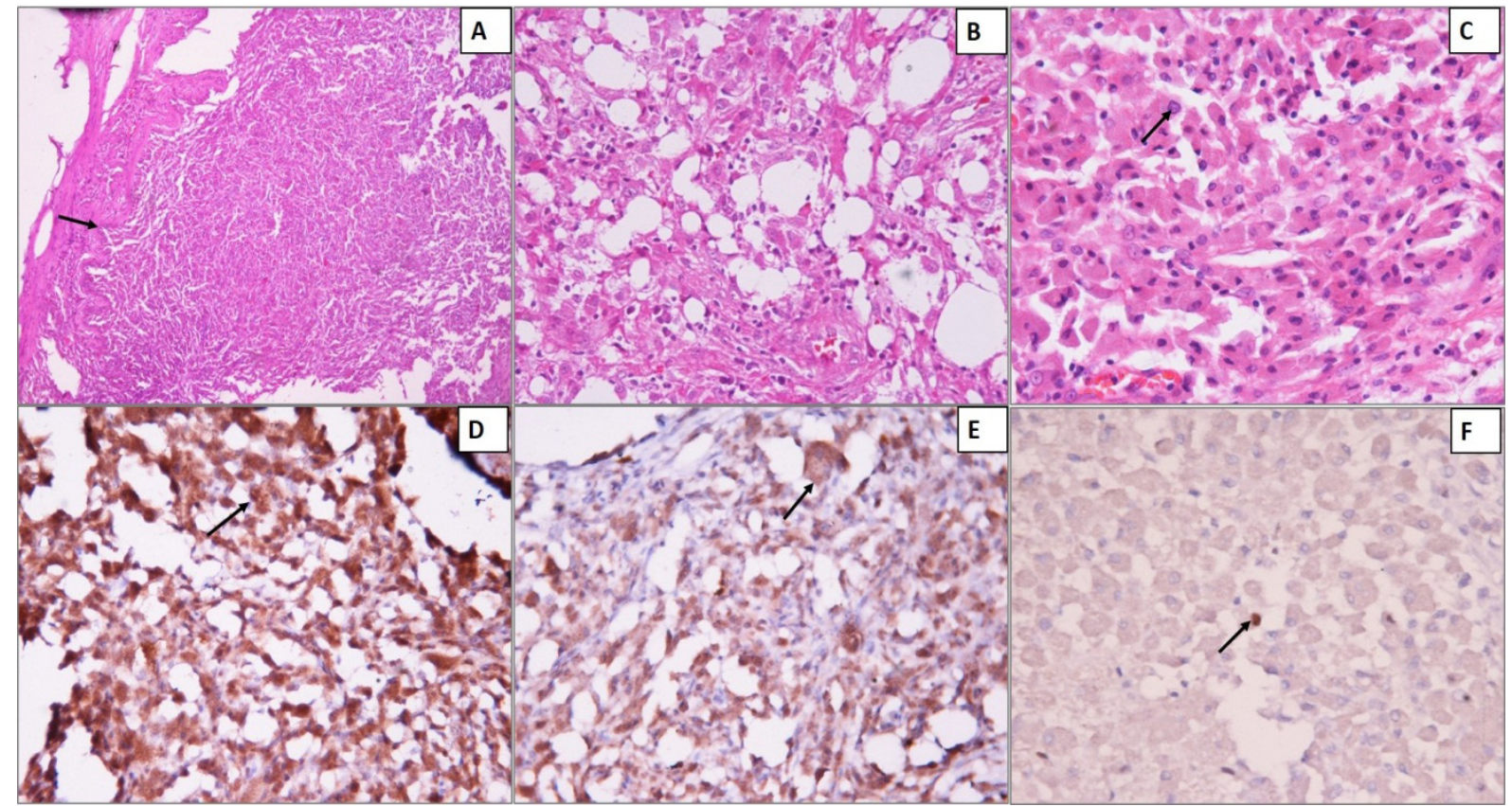

Figure 1: Mastectomy specimen showing a partially encapsulated tumor (capsule marked with arrow) (A) (H\&E, 10x); Focal infiltration into adipose tissue of adjacent breast parenchyma (B) (H\&E,20x); The tumour cells are arranged in diffuse sheets, composed of polygonal cells with abundant eosinophilic cytoplasm and round nuclei with inconspicuous nucleoli (arrow) (C) (H\&E, 40x). These cells show predominant cytoplasmic positivity (arrow) and focal nuclear immunopositivity for S100 (D) (IHC, 20x) and Calretinin (E) (IHC, 20x); Ki67 labelling index is low, with occasional nuclear staining (arrow) (F) (IHC,40x)

\section{Discussion}

GCT is an uncommon tumour of the breast with good prognosis. These tumours most commonly occur in women between 30 and 50 years of age i.e. in the pre and perimenopausal age group [3]. Most of the time GCT of the breast is located in the inner quadrant of the breast due the close association of supraclavicular nerves. Most of the GCT of the breast are benign tumours with less than $1 \%$ are malignant [4]. Tumour transformation from benign to malignant variety is rare.

The histological criteria of malignant granular cell tumour were established in 1998 by Fanburg-Smith, et al. [5] which included necrosis, spindling, vesicular nuclei with large nucleoli, increased mitotic activity ( $>2$ mitoses/10HPF at 200 $\times$ magnification), high nuclear to cytoplasmic ratio and pleomorphism. However, these criteria may not hold value in every case and the histological diagnosis of the malignant lesion can be challenging in the present case which closely resembled its benign counterpart. In addition to this features of local recurrence, metastasis, large tumour size, older patient age and Ki 67 values greater than $10 \%$ being regarded as statistically significant adverse prognostic factors. Tumour lesions which met three or more of these criteria were classified as histologically malignant; those of atypical variety has one or two of the features; and those that displayed only focal pleomorphism but fulfilled none of the above mentioned criteria were classified as benign.

In this patient, the tumour had all the features of benign tumor except the size of the lesion, which was around $4 \mathrm{~cm}$ and developed recurrence in a year span.

There are only a few such cases reported in the literature which are histologically benign but with malignant features clinically. Simsir A, et al. [6] reported a GCT of the orbit which was histologically benign based on fanburg definition but was termed malignant based on the locally advanced lesion. Jardines L, et al. [7] reported soft tissue GCT with uncertain malignant potential histologically but had regional nodal metastasis radiologically. Akahane K, et al. [8] reported an atypical GCT of the breast with clinical features of malignancy. This report concluded that high level Ki-67 alone was considered as a proof of malignancy. Chen J, et al. [9] reported the simultaneous appearance of two benign lesions namely in the breast and abdominal wall. Due to multiple recurrences, this case of benign GCT was classified as malignant. It was presumed that malignant GCT results from the transformation of benign GCT.

In considering the above reported cases and the present case, classifying GCT as malignant based only on histological features must be debated. So this kind of malignant potential GCT must be identified. In this patient, the tumour recurred after a disease free interval of one year. There are some reports about transformation of benign GCT to malignant nature, so considering all the facts radiation therapy was given to the chest wall. On follow up of more than 16 months, she is disease free.

\section{Conclusion}

GCT of the breast is a rare neoplasm. Physician must be vigilant of this benign GCT with malignant potential tumour. The patient must have a close follow up especially in the first 2 years. 


\section{References}

1. Papalas JA, Wylie JD, Dash RC (2011) Recurrence risk and margin status in granular cell tumors of the breast: a clinicopathologic study of 13 patients. Arch Pathol Lab Med 135: 890-5.

2. Mátrai Z, Langmár Z, Szabó E, Rényi-Vámos F, Bartal A, et al. (2010) Granular cell tumour of the breast: case series and review of the literature. Eur J Gynaecol Oncol 31: 636-40.

3. Kragel PJ, Fiorella RM, Kremer H (1995) Tumoral fibrosis and lack of circumscription in granular cell tumor of the breast. South Med J 88: 1146-8.

4. Goldblum J, Folpe A (2014) Enzinger and Weiss's Soft Tissue Tumors $6^{\text {th }}$ edition.

5. Fanburg-Smith JC, Meis-Kindblom JM, Fante R, Kindblom LG (1998) Malignant granular cell tumor of soft tissue: diagnostic criteria and clinicopathologic correlation. Am J Surg Pathol 22: 779-94.

6. Simsir A, Osborne BM, Greenebaum E (1996) Malignant granular cell tumor: A case report and review of the recent literature. Hum Pathol 27: 853-8.

7. Jardines L, Cheung L, LiVolsi V, Hendrickson S, Brooks JJ (1994) Malignant granular cell tumors: report of a case and review of the literature. Surgery 116: 49-54. 8. Akahane K, Kato K, Ogiso S, Sakaguchi K, Hashimoto M, et al. (2015) Malignant granular cell tumor of the breast: case report and literature review. Breast Cancer 22: 317-23.

9. Chen J, Wang L, Xu J, Pan T, Shen J, et al. (2012) Malignant granular cell tumor with breast metastasis: A case report and review of the literature. Oncol Lett 4: 63-6.

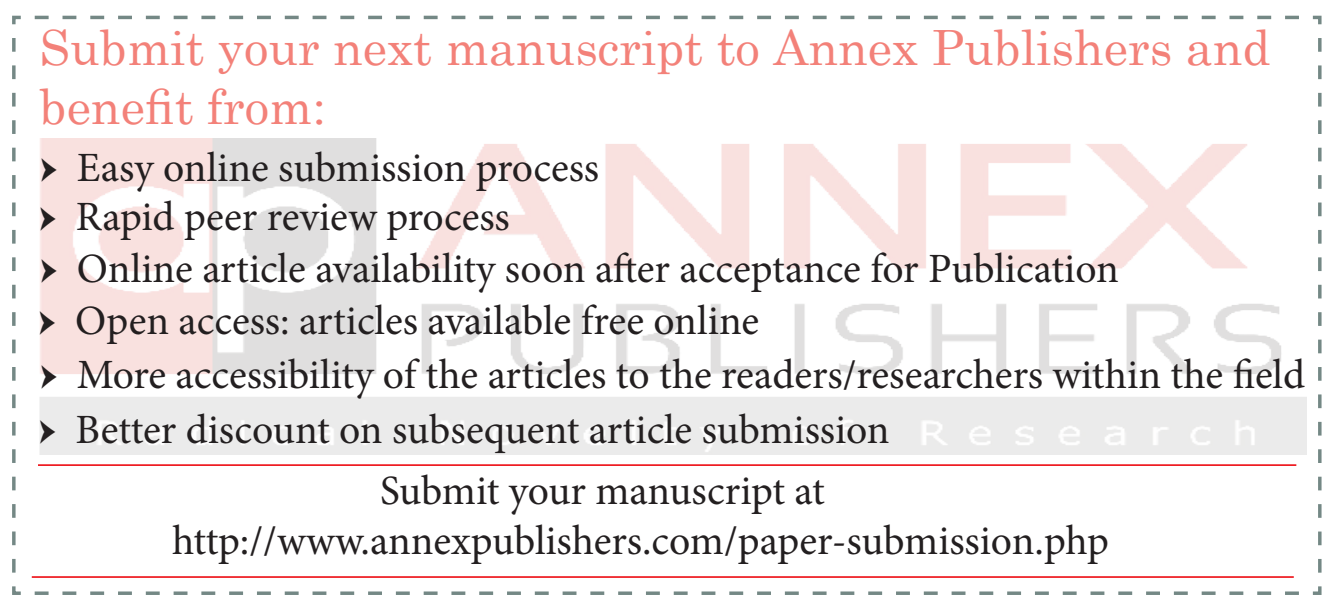

